\title{
RELAÇÃO ENTRE O CONSUMO DE ÁGUA E MELHORA DA CAPACIDADE COGNITIVA EM ESTUDANTES
}

\begin{abstract}
Jairo Bressan
Pós-Graduaçāo, Universidade do Extremo Sul Catarinense, jairo.bressan@satc.edu.br Joni Marcio de Farias Doutor, Universidade do Extremo Sul Catarinense, jmf@unesc.net Geiziane Laurindo de Morais Graduanda, Universidade do Extremo Sul Catarinense, geisi.morais@hotmail.com
\end{abstract}

\section{RESUMO}

A relaçáo entre consumo de água e melhora da capacidade cognitiva em estudantes tem chamado a atenção atualmente, pois a hidratação ao longo do dia pode afetar o desempenho cognitivo, com alteração no processo de ensino e aprendizagem em estudantes, ou seja, o consumo de água pode resultar em benefícios da memória e da atenção em crianças, justificando que a água é fundamental para que o cérebro se mantenha alerta. Alguns estudos demonstraram a importância do consumo de água, mas náo encontraram evidências entre a capacidade de manter a atenção e o consumo de água. Grande parte dos estudos relacionou a desidratação suave com efeito negativo nas crianças, em relaçáo ao desempenho cognitivo, demonstrando que um grupo desidratado tem uma significância ruim no desempenho, enquanto pessoas hidratadas apre- 
sentaram melhores desempenhos, principalmente em medidas de flexibilidade semântica. Devido à inconsistência nos achados, à falta de evidências científicas que afirmam a relaçấo entre o consumo de água e a capacidade cognitiva, bem como à quantidade ideal de água para o consumo em estudantes, justifica-se uma investigaçấo mais detalhada da efetividade do consumo de água e desempenho cognitivo, contribuindo para a criaçáo de estratégias que orientem os escolares sobre a temática, por meio de métodos que influenciam o estado de hidratação das crianças para reduzir o risco de desidratação leve, assim como modifiquem as práticas pedagógicas, contribuindo para a melhora do desempenho escolar.

Palavras-chave: Água; Estudantes; Cognição. 